\title{
Imagining sustainable human ecosystems with power-to-x in-situ resource utilisation technology
}

\author{
Mark Baldry ${ }^{a, b,},{ }^{*}$, Nicholas Gurieff ${ }^{c}$, Declan Keogh ${ }^{d}$ \\ ${ }^{a}$ School of Physics, University of Sydney, Sydney, New South Wales 2006, Australia \\ ${ }^{b}$ School of Biomedical Engineering, University of Sydney, Sydney, NSW 2006, Australia \\ ${ }^{c}$ Priority Research Centre for Frontier Energy Technologies \& Utilisation, The University of Newcastle, \\ Callaghan, New South Wales 2308, Australia \\ ${ }^{d}$ School of Mechanical and Manufacturing Engineering, UNSW, Sydney, NSW 2052, Australia \\ *Corresponding author mark.baldry@sydney.edu.au
}

\begin{abstract}
Extensive in-situ resource utilisation (ISRU) will be essential to enable long-duration stays on Luna and Mars and reduce reliance on resupply from Earth. Early development of ISRU technologies has focused on standalone capabilities for specific targets related to life support and ascent propellant. An unexplored opportunity remains for greatly expanding the scope of materials that can be supplied by ISRU, and for integrating various technology platforms into a larger system. Recent advances in powerto-X technology aimed at decarbonising the global economy have made it possible to drive key chemical processes using electricity with small-scale, modular reactor. This paper proposes a vision for an integrated system of ISRU processes based on power-to-X technology to produce oxygen, hydrogen, water, methane, polymers, metal alloys, and synthetic fertilisers, using Martian regolith, atmosphere, and ice. A 'building block' strategy is adopted to convert raw materials into versatile intermediaries, which can then be combined to form essential products. A wider range of raw materials are available on Mars compared to Luna, suggesting greater opportunity for ISRU deployment to compensate for the greater time and cost requirements for a Mars resupply mission.
\end{abstract}

\section{Keywords}

Power-to-X; Space; energy storage; in-situ resource utilisation; ammonia; circular economy;

\section{Introduction}

\subsection{Overview}

Eliminating a crew's reliance on supply chains from Earth for critical supplies is essential to ensuring the feasibility of long-duration or permanent settlements on the Moon (Luna) and Mars [1-5]. This paper explores the potential for emerging power-to- $X$ technologies to enable material self-sufficiency in extra-planetary settlements. Power-to-X (P2X) refers to a range of systems whereby electrical energy is used to directly drive chemical or physical processes [6-8], such as the electrolysis of water to produce $\mathrm{H}_{2}$ and $\mathrm{O}_{2}$. Broad adoption of $\mathrm{P} 2 \mathrm{X}$ could provide large-scale renewable energy storage $[6,7,9,10]$ and the 'greening' of major emissions-intensive industries that rely on fossil fuel derivatives $[7,11,12]$. These processes can be scaled down and driven by alternative electricity sources, making it particularly attractive for space missions and remote terrestrial locations. Recent advances in P2X have combined nonthermal plasma [13] and electrolysis processes with novel catalysts, greatly expanding the range of potential applications [11]. This study explores the potential role of P2X in achieving in-situ resource utilisation (ISRU) at Martian or Lunar settlements. The focus here is on the key ISRU output targets outlined by the NASA Design Reference Architecture 5.0 for a Mars mission: $\mathrm{H}_{2} \mathrm{O}, \mathrm{O}_{2}, \mathrm{CH}_{4}$, and buffer gases for life support, extra-vehicular activities, and ascent propellant $[4,5,21]$. Additional requirements for permanent settlements are also considered, namely carbon and nitrogen sources for agricultural development [5,22], hydrogen for fuel and energy storage [23], and metals, which can be produced synergistically with oxygen and other materials. It is assumed that 
supply chains and sustainable energy sources (such as solar photovoltaics and radioisotope thermoelectric generators) are available to facilitate the transport of resources across the planetary surface, and to satisfy the power requirements for ISRU, respectively. Costs of technology development along with launch weight, formal technological readiness assessment, and transportation from Earth are also left for future work. The aim of this study is to explore the possibilities for integrating modular ISRU technologies to convert local resources into molecular building blocks, which can be used to supply the material requirements of Lunar or Martian settlements.

\subsection{In-situ resource availability}

The variability of in-situ resource availability profiles on different planetary bodies may require different approaches to ISRU. Here we identify the resources available on Luna and Mars, the most relevant mission destinations in the near future [2].

\subsubsection{Luna}

The lunar regolith comprises fine-grained particles (average grain size $60 \mu \mathrm{m}$, specific heat capacity $0.9 \mathrm{~kJ} \cdot \mathrm{kg}^{-1} \cdot \mathrm{K}^{-1}$, density $1660 \mathrm{~kg} \cdot \mathrm{m}^{-3}$ [5]) and rocks between 3 and $20 \mathrm{~m}$ deep across the surface of the moon [23]. Extensive analysis of the regolith composition has been carried out on recovered samples from the Apollo missions and from orbiting satellites, highlighting significant spatial variation [5]. The Lunar terrain is composed of lighter 'highlands' and darker 'maria' with significant amounts of mineral oxides [24,25], containing $41-44 \%$ oxygen content [26]. Significant water ice deposits have been detected at the polar regions and in permanently shadowed craters; the Lunar Crater Observation and Sensing Satellite (LCOSS) recently measuring $5.6 \pm 2.9 \mathrm{wt} \% \mathrm{H}_{2} \mathrm{O}$ at the southern Lunar Cabeus crater, most likely present as small-grained crystals $[5,23]$. Water recovered by extraction from hydrated minerals or reduction of mineral oxides is considered less technically challenging compared to directly accessing shadowed craters, despite large reserves of crater ice $[5,23]$. The Lunar maria are generally classified as basaltic, comprising the minerals ilmenite, olivine, and pyroxene [23] and therefore rich in silicon, iron, calcium, aluminium, magnesium, and titanium. The elemental composition of Lunar highlands are instead predominantly rich in plagioclase minerals [23], with the dominant mineral being anorthite $\left(\mathrm{CaAl}_{2} \mathrm{Si}_{2} \mathrm{O}_{8}\right)$, and contains mostly silicon, aluminium, and calcium, along with smaller quantities of iron and magnesium [5]. The regolith also contains sodium, potassium, phosphorous, manganese, chlorine, and chromium [26], along with trace amounts of solar-wind implanted volatiles. These volatiles include carbon, nitrogen, hydrogen, helium, fluorine, neon, argon, krypton, xenon, and sulphur that are typically found in titanium-bearing ilmenite and volcanic pyroclastic deposits [5], which can be extracted with direct thermal processing at $300-900^{\circ} \mathrm{C}[5,23]$.

\subsubsection{Mars}

The Martian atmosphere is $95 \%$ carbon dioxide with an average surface atmospheric pressure of 608 $\mathrm{Pa}$, or $0.6 \%$ of Earth's atmosphere [22], an average surface temperature ranging between $-73^{\circ} \mathrm{C}$ to $17^{\circ} \mathrm{C}[2,22], 590 \mathrm{~W}$ solar irradiation and $38 \%$ earth's gravity [2]. The Martian surface is covered in a layer of regolith with grain size varying from 1 to $1000 \mu \mathrm{m}$ and bulk density 1.2 to $1.6 \mathrm{~g} / \mathrm{cm}^{3}$ [2]. Water is present on Mars as solid water ice in polar regions, as mineral hydrates in lower latitudes, and in the atmosphere as vapour [27]. Martian regolith contains around $1 \%$ water [22] and up to $8 \%$ at low latitude gypsum dunes [28]. A wide variety of minerals have been identified on Mars, however a detailed description of Martian geology is beyond the scope of this work and has been covered elsewhere $[29,30]$. Here the native resources of interest for ISRU applications are outlined, mostly limited to the easy-to-access regolith. Mars' surface is predominantly composed of basaltic materials 
[30], rich in olivine, pyroxene and magnetite [29], and is divided into sulphur rich (SR) and haematite rich (HR) regolith [30]. Direct measurements of the surface composition have been carried out by surface rovers, with attempts to differentiate between Martian soil and rock, which have different compositions. The Mars Pathfinder analysed rock samples in the regolith of the Ares Vallis region in 1997 and found the major component was silicon dioxide (57-57.7\%), followed by iron oxide (14.2$15.7 \%)$, alumina (11-12.3\%), calcium oxide (6.7-8.1\%), sodium oxide (2.5-4.2\%), along with small amounts $(<2 \%)$ of other materials including magnesium oxide, phosphorous pentoxide, sulphur, chlorine, potassium oxide, titanium dioxide and manganese oxide [29]. The NASA Spirit and Opportunity rovers also carried out chemical analysis of Martian soil at the Gusev crater and Meridiani Planum region, respectively, finding similar material composition, with stronger concentrations of magnesium oxide (7.6-8.5\%) along with sulphur trioxide (5.6-6.3\%) and trace amounts of chromium oxide and nickel oxide [29,31]. Analysis of the sulphur rich Paso Roble regolith by the Spirit rover found very high $\mathrm{SO}_{3}$ concentrations of $\sim 31.7 \%$, along with enriched phosphorous pentoxide [30], indicating significant spatial variability on the surface. $\mathrm{Mg}$-Fe carbonate materials have also been detected in the Columbia Hills region of Mars' Gusev crater by the Spirit rover, reaching 16-34\% concentration in the Comanche outcrops of the crater and equivalent to around 3\% pure carbon [32]. The more recent NASA Curiosity rover has carried out mineralogical analysis of Martian soil in the Gale crater, specifically the Ganold Dune field [33]. The average composition at two sites (Rocknest and Gobabeb) was predominantly silicon dioxide $(43 \%)$, followed by iron oxide $(19 \%)$, aluminium oxide $(9 \%)$, magnesium oxide $(8.6 \%)$, calcium oxide $(7 \%)$, sulphur trioxide $(5.8 \%)$, sodium oxide $(2.7 \%)$, and small $(<\sim 1 \%)$ amounts of titanium dioxide, manganese oxide, potassium oxide, phosphorous pentoxide, chromium oxide, chlorine, and trace amounts of nickel, zinc and bromine [33,34].

\section{Technologies for ISRU processing}

A suite of material processing technologies is available at various stages of maturity for use in ISRU conversion applications. We include those processes that could deliver specific capabilities in life support (oxygen, water, food including fertiliser), fuels for propulsion, structural materials for building tools and habitats, hygiene, and comfort. This section proposes relevant technologies and provides a brief overview of their function. Electrically driven processes are favoured where possible, to take advantage of their modularity and controllability compared to conventional thermochemical conversion.

\subsection{Direct extraction}

The direct extraction of resources through thermal or physical processes can be used to source water on both Luna and Mars, as well as carbon dioxide and nitrogen from the Martian atmosphere. On both Luna and Mars, water is present as mineral and pyroclastic hydrates [5,27], and water ice [23], to varying extents, which can be extracted through simple heating and purification. Unlike Luna, the Martian atmosphere is a potential primary source of molecular building blocks, composed of $95.3 \%$ $\mathrm{CO}_{2}, 2.7 \% \mathrm{~N}_{2}, 1.6 \% \mathrm{Ar}$, with trace amounts ( $\left.<1 \%\right)$ of $\mathrm{O}_{2}, \mathrm{CO}, \mathrm{H}_{2} \mathrm{O}$, and $\mathrm{NO}$ [27]. This can be compressed and used as a $\mathrm{CO}_{2}$ source for electrolysis as in the Mars Oxygen In-Situ Resource Utilisation Experiment (MOXIE) unit currently deployed on Mars as part of the NASA Perseverance rover, which will be discussed in Section 2.3. Solar implanted volatiles in lunar regolith returned from Apollo missions have been extracted by heating to around $700^{\circ} \mathrm{C}$, liberating hydrogen, nitrogen, carbon, and sulphur sources that may be deployed for fuel or agricultural feeds [5], however efficient separation and concentration of these materials remains an unsolved technical challenge. Lunar regolith can also be melted to produce transparent glass at $1600^{\circ} \mathrm{C}$, which can act as in-situ substrate for thin-film PV panels manufactured directly on the lunar surface $[35,36]$. Both Lunar and Martian regolith have also 
been explored for use as a 3D printing material to produce habitats and structural materials robotically $[2,22,26,34,37,38]$.

\subsection{Conventional thermochemical processing}

Conventional thermochemical processes on Earth are often deployed at large scale with complex infrastructure, high operating temperatures and pressures, and consistent operating conditions. This may pose a challenge for their use in space applications where safety, reliability, and compactness are required. Sabatier methanation (Eq. 1) is a mature thermocatalytic process for synthesising methane from carbon dioxide and hydrogen, typically at $400^{\circ} \mathrm{C}-500^{\circ} \mathrm{C}$ and $10-30$ atm [36,39-41], and an example of flight-tested thermocatalytic ISRU technology.

$\mathrm{CO}_{2}+4 \mathrm{H}_{2} \rightleftharpoons \mathrm{CH}_{4}+2 \mathrm{H}_{2} \mathrm{O}$

A small scale Sabatier reactor was used on the international space station from 2010-2017 to produce water for life support $[36,42]$. NASA is developing Sabatier technology for in-situ production of ascent propellant on Mars using hydrogen from locally derived water and atmospheric carbon dioxide $[41,43]$. The production of rocket fuel for ascent from the Martian surface would significantly reduce the costs and improve the feasibility of a Mars return mission [24] since around 225 tonnes of fuel would be consumed to deliver a single tonne of fuel to the Martian surface [28].

Several thermochemical processes have been explored for their potential to extract oxygen from Lunar and Martian regolith [3,5,24]. Some examples of this for the ilmenite mineral $\left(\mathrm{FeTiO}_{3}\right)$ include reduction with hydrogen followed by water electrolysis $\left(2 \mathrm{H}_{2} \mathrm{O} \rightarrow 2 \mathrm{H}_{2}+\mathrm{O}_{2}\right)$,

$\mathrm{FeTiO}_{3}+\mathrm{H}_{2} \stackrel{900^{\circ} \mathrm{C}}{\longrightarrow} \mathrm{Fe}+\mathrm{TiO}_{2}+\mathrm{H}_{2} \mathrm{O}$

reduction with methane (Eq. 3),

$\mathrm{FeTiO}_{3}+\mathrm{CH}_{4} \stackrel{1600^{\circ} \mathrm{C}}{\longrightarrow} \mathrm{Fe}+\mathrm{TiO}_{2}+\mathrm{CO}+2 \mathrm{H}_{2}$

and vapour phase pyrolysis at high temperature (Eq. 4),

$\mathrm{FeTiO}_{3} \stackrel{2000^{\circ} \mathrm{C}}{\longrightarrow} \mathrm{Fe}+\mathrm{TiO}_{2}+\frac{1}{2} \mathrm{O}_{2}$

Despite the many potential avenues for thermochemical processing of regolith, electrolytic methods have emerged as potentially more suitable due to their relative simplicity [24], and these are described below.

\subsection{Electrolysis}

Electrochemical processes are highly attractive for terrestrial P2X and space ISRU applications due to their versatility [44]. The simplest example is the direct electrolysis of water to produce oxygen and hydrogen gas. Electrolysis of water ice in shadowed Lunar craters and on Mars could produce oxygen for life support and hydrogen as input to fuel production. However, extracting $\mathrm{O}_{2}$ and $\mathrm{H}_{2}$ from regolith may yield additional useful by-products, and avoids the challenge of accessing water ice in shadowed Lunar craters [23], instead of relying on ubiquitous regolith materials. Here we introduce selected electrolysis processes with potential for deployment in space settlements.

On Earth, direct air capture (DAC) is currently being considered as a negative emissions technology (NET) to extract $\mathrm{CO}_{2}$ from the atmosphere. Commodity products such as methane or liquid fuels could then be produced from the extracted $\mathrm{CO}_{2}$ through hydrogenation. The MOXIE experiment currently underway on Mars captures and compresses the $\mathrm{CO}_{2}$ rich Martian atmosphere and then converts it to 
carbon monoxide and oxygen (Eq. 5) using a solid oxide fuel cell [21,45,46]. Carbon dioxide produced by astronauts could also be captured and converted, as was done on the international space station between 2010-2017.

$$
\mathrm{CO}_{2} \rightarrow \mathrm{CO}+\frac{1}{2} \mathrm{O}_{2}
$$

Carbon dioxide can also be co-electrolysed (Eq. 6) with water in the presence of a catalyst to produce syngas (carbon monoxide and hydrogen in various ratios [47]) directly [21,48],

$4 \mathrm{H}_{2} \mathrm{O}+2 \mathrm{CO}_{2} \rightarrow 4 \mathrm{H}_{2}+2 \mathrm{CO}+3 \mathrm{O}_{2}$

which can subsequently be used for methane synthesis via the Sabatier process (Eq. 1). Conventionally, $\mathrm{CO}_{2}$ reduction and $\mathrm{H}_{2}$ evolution occur at the anode, with the oxygen evolution reaction occurring at the cathode and consuming around $90 \%$ of the input power to the cell. Alternative anode reactions are possible, such as glycerol oxidation, which reduces the energy consumption by over $50 \%$. However, these may not be suitable for space applications considering the additional material requirements compared to Eq. 6, which can proceed with local resources. Apart from solid oxide electrolysers such as MOXIE, alternative electrochemical reactors have been proposed for $\mathrm{H}_{2} \mathrm{O} / \mathrm{CO}_{2}$ co-electrolysis, including gas diffusion electrodes, membrane reactors, and flow cells [48], the latter of which may be considered most mature and can borrow from recent developments in fuel cells and electrolysers. The electrochemical methanation of $\mathrm{CO}_{2}$ is another potential avenue for producing methane from in-situ materials on Mars, which could then be used for ascent vehicle propellant [43]. The electrocatalytic methanation of carbon dioxide has been proven at industrial scale by the $6 \mathrm{MW}$ Audi plant in Germany, using $\mathrm{CO}_{2}$ from biomass to produce up to 1000 tonnes of methane per year [7]. Methanol could also be used for energy storage or as a chemical building block, produced electrochemically from $\mathrm{CO}_{2}$ and $\mathrm{H}_{2}$ (Eq. 7) [49].

$\mathrm{CO}_{2}+3 \mathrm{H}_{2} \rightleftharpoons \mathrm{CH}_{3} \mathrm{OH}+\mathrm{H}_{2} \mathrm{O}$

Lunar and Martian regolith are rich in metal oxides [24,29], suggesting there is a significant opportunity to co-produce breathable oxygen, and metals from ubiquitous regolith materials [44]. Electrolytic reduction of molten regolith (molten oxide electrolysis, $\mathrm{MOE}$ ) is a simple, compact, and continuous process with limited input requirements that is compatible with a range of feedstocks, making it highly attractive for processing Lunar $[3,25]$ and Martian regolith $[44,50]$. MOE is currently the cheapest way to produce oxygen on Mars or Luna from in-situ resources, with up to $95 \% \mathrm{O}_{2}$ recovery [24], and the process produces useful metal alloys for manufacturing [51]. A simplified, indicative overall reaction for $\mathrm{MOE}$ of iron oxide $(\mathrm{FeO}$ ) is shown for the cathode (Eq. 8) and anode (Eq. 9) from $[24,44]$.

$$
\begin{aligned}
& \mathrm{Fe}^{2+}+2 \mathrm{e}^{-} \rightarrow \mathrm{Fe}^{0} \\
& \mathrm{O}^{2-} \rightarrow \frac{1}{2} \mathrm{O}_{2}+2 \mathrm{e}^{-}
\end{aligned}
$$

\subsection{Plasma processing and catalysis}

Nonthermal 'cold' plasma is used in industry to eliminate volatile organic compounds and nitrogen oxides [52,53], treating wastewater [54,55], generating ozone for disinfection [53,56], and could be used to manage airborne pollutants in space life support systems. The selective heating of electrons in a nonthermal plasma generates significant populations of energetic species, enabling lowtemperature activation of stable molecules and alternative pathways to overcome thermodynamically unfavourable reactions [52,57-59]. Incorporating catalyst materials into plasma reactors, known as 
plasma catalysis (PC), shows significant promise for activating stable molecules such as $\mathrm{N}_{2}$ and $\mathrm{CO}_{2}$ and converting them into valuable materials for use in agriculture, transport, and chemical synthesis $[13,39,52,56-65]$. PC processes are attractive for remote applications [57] such as a Lunar or Martian settlement because they are modular and small $[57,66]$, can be cycled rapidly $[60,67]$, are compatible with intermittent power $[9,66]$, and are operated at low temperatures and atmospheric pressure $[9,12,13,52,68]$, eliminating the cost, size, and complexity associated with conventional thermochemical plant equipment.

\section{Discussion}

\subsection{Overview}

In this section an integrated chemical processing system based on the technologies described above is proposed to reduce the reliance of a Martian settlement on resupply from Earth. The objective of this section is to demonstrate how abundant in-situ resources may be used to support life support systems, produce ascent propellant, supply key chemicals for agricultural development, and form the basis of chemical engineering capability based on simple hydrocarbons. This approach is referred to as a 'building block' strategy, whereby raw materials are converted into small, versatile molecules that can be converted into more complex products. This builds upon the recent work by Hartvigsen et al. [21] that proposed combining co-electrolysis of $\mathrm{H}_{2} \mathrm{O}$ and $\mathrm{CO}_{2}$ with either a methanation or FischerTropsch reactor to directly produce oxygen and hydrocarbons. This system was shown to provide the daily oxygen requirement for an average adult with a power consumption of about $159 \mathrm{~W}$. It was proposed for use with $\mathrm{CO}_{2}$ from the Martian atmosphere or from astronaut exhalation in the context of long-duration spaceflight [21]. This small-scale example shows how integration of modular processes could supply life support systems and use in-situ resources. A high-level concept design for an integrated chemical processing system for a Martian settlement is proposed in Fig. 1. This conceptual system design explores the possibilities of leveraging emerging electrochemical and plasma-catalytic processes to achieve ISRU, particularly for the goals stated above. It is assumed that sustainable energy sources are available to supply the ISRU system depicted in Fig. 1, and that energy flows will be engineered to maximise economisation wherever possible. Methanol has been selected as the target molecule for $\mathrm{CO}_{2}$ hydrogenation as it is a highly versatile precursor for many mature industrial hydrocarbon processes $[69,70]$. Methanol can be used as a solvent or in the production of formaldehyde, synthetic resins, polyesters, silicone rubber, and other plastics [69]. Fig. 1 shows the conversion of methanol to olefins (such as ethylene) to produce polymers for manufacturing a wide range of products. Other oxygenates such as ethanol, acetone, and acetic acid can also be produced from $\mathrm{CO}_{2}$ and $\mathrm{CH}_{4}$ with plasma catalysis [58] for use as industrial solvents, cleaning products, and pharmaceuticals production [70]. 


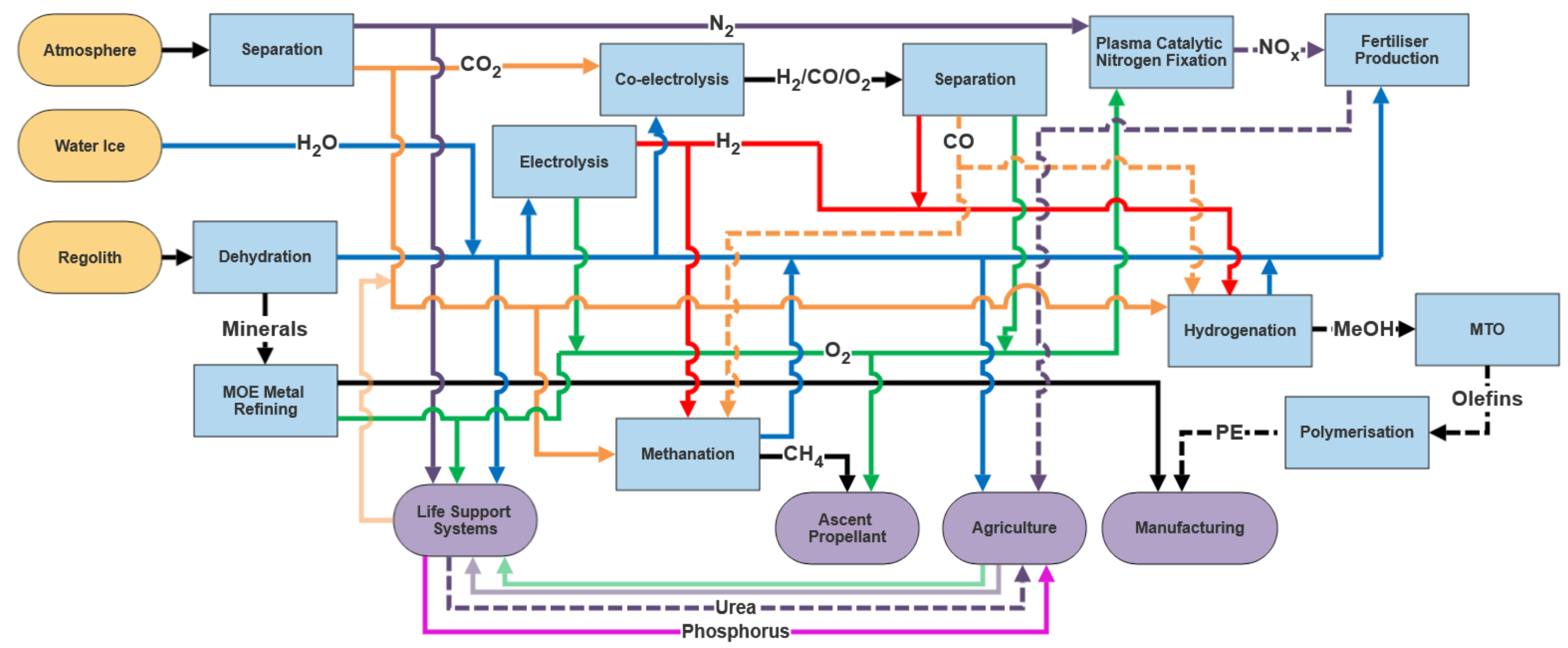

Figure 1: Concept design for integration of material synthesis processes for Mars. Translucent lines indicate recycle loops. Material streams are colour coded as indicated. In the lunar context there is no atmosphere meaning that there is no abundant source of carbon or nitrogen, resulting in a substantially simplified system. 


\subsection{Primary processing of raw materials}

In the current scheme (Fig. 1) for a Martian habitat, raw materials are sourced primarily from the atmosphere, regolith, and water ice. Separation and activation processes are required to convert these raw materials into useful products, beginning with the electrolysis of water ice to $\mathrm{O}_{2}$ and $\mathrm{H}_{2}$. The principal uses of $\mathrm{O}_{2}$ considered here are life support, ascent vehicle oxidant, and fertiliser production. Considering $80 \%$ of launch vehicle mass is fuel and oxygen, with the majority $(7 / 8)$ being $\mathrm{O}_{2}$ [24], insitu production of $\mathrm{O}_{2}$ along with fuel $\left(\mathrm{CH}_{4}\right)$ is essential.

Regolith is an abundant source of metals, oxygen, and water, so initial processing would involve dehydration followed by molten oxide electrolysis to extract $\mathrm{O}_{2}$ and produce metallic alloys for manufacturing. Ferrosilicon alloys produced from MOE can be used to produce feedstocks for additive manufacturing from abundant iron and silicon oxides in Lunar and Martian regolith [51]. Early work on regolith electrolysis highlighted significant engineering challenges associated with the containment of highly corrosive, high-temperature molten oxides $[3,25]$. These were overcome with cold-walled reactors that use cooled regolith to protect the vessel walls from molten oxide, much like the HallHeroult cells used in aluminium refining [24,50,51]. Schreiner et al. [24] simulated cold walled MOE reactors under a wide range of operating conditions showing the process was robust to regolith composition and recovered between 0.15 and $0.375 \mathrm{~kg} \mathrm{\textrm {O } _ { 2 }}$ per $\mathrm{kg}$ of regolith.

The Martian atmosphere is predominantly $\mathrm{CO}_{2}(95.3 \%)$, with $2.7 \% \mathrm{~N}_{2}$ that can be separated and directed towards co-electrolysis and nitrogen fixation processes, respectively. Purified oxygen and water would directly supply life support systems and nitrogen gas would be used as an atmospheric buffer gas for habitats. Co-electrolysis of $\mathrm{CO}_{2}$ and $\mathrm{H}_{2} \mathrm{O}$ with a solid oxide electrolyser (such as the MOXIE experiment) can produce syngas, along with $\mathrm{O}_{2}$. In addition to supplying the life support systems and nitrogen fixation process (discussed later), oxygen would be allocated for use as oxidant in ascent propellant systems.

\subsection{Producing ascent propellant}

Hydrogen gas produced from co-electrolysis (and water electrolysis) can be combined with extracted atmospheric carbon dioxide in a Sabatier methanation reactor to produce methane gas for ascent propellant as discussed in Section $2.2[41,43]$. Thermocatalytic methanation of $\mathrm{CO}_{2}$ at low pressure with selectivity and conversion close to theoretically optimum values has already been achieved industrially [71]. Plasma-catalytic methanation has recently been shown to improve $\mathrm{CO}_{2}$ activation, achieve $97 \%$ methane selectivity over $\mathrm{CO}$ and $60 \%$ conversion of $\mathrm{CO}_{2}$, and be carried out at significantly lower temperatures than the conventional process $\left(150^{\circ} \mathrm{C}\right.$ vs $\left.320^{\circ} \mathrm{C}\right)$ [39]. A lower operating temperature imparts a thermodynamic advantage for the methanation reaction and may improve the longevity of the catalyst (nickel or ruthenium for maximal methane selectivity), avoiding sintering and coking typically associated with higher operating conditions [40]. Carbon dioxide methanation is mechanistically a two-step process occurring in a thermochemical reactor, comprising the reverse water-gas shift reaction (RWGS Eq. 10) and the methanation of carbon monoxide (Eq. 11) [40]. This suggests that the syngas produced by the co-electrolysis stage in the proposed scheme could also be used for methane production, assuming the stoichiometric ratios are adjusted.

$$
\begin{aligned}
& \mathrm{H}_{2}+\mathrm{CO}_{2} \rightleftharpoons \mathrm{CO}+\mathrm{H}_{2} \mathrm{O} \\
& 3 \mathrm{H}_{2}+\mathrm{CO} \rightarrow \mathrm{CH}_{4}+\mathrm{H}_{2} \mathrm{O}
\end{aligned}
$$




\subsection{Methanol as a versatile building block for hydrocarbon chemistry}

Methanol is mainly produced industrially from natural-gas derived syngas [47] using a hydrogenation process over a $\mathrm{Cu} / \mathrm{ZnO} / \mathrm{Al}_{2} \mathrm{O}_{3}$ catalyst at moderate temperatures and high pressures $[72,73]$. The overall reaction is described by Eq. 12 , however it is a two-step process. The water-gas shift reaction (reverse of Eq. 10) converts carbon monoxide into carbon dioxide that is subsequently hydrogenated to form methanol $\left(\mathrm{CO}_{2}+3 \mathrm{H}_{2} \rightarrow \mathrm{CH}_{3} \mathrm{OH}+\mathrm{H}_{2} \mathrm{O}\right)[47,69,71]$. Carbon dioxide is also commonly present in the syngas feed for industrial methanol reactors $[47,69,74]$ and improves the methanol synthesis rate $[69,75]$.

$\mathrm{CO}+2 \mathrm{H}_{2} \rightarrow \mathrm{CH}_{3} \mathrm{OH}$

Hydrogenation of pure $\mathrm{CO}_{2}$ to methanol $(\mathrm{MeOH})$ is as a potential negative emissions technology [69], however the higher cost associated with capturing atmospheric $\mathrm{CO}_{2}$ and generating green $\mathrm{H}_{2}$ has limited its adoption $[72,73]$. Recent developments in catalysis and optimisation of the thermochemical $\mathrm{CO}_{2}$-to-methanol conversion processes have resulted in single-pass $\mathrm{CO}_{2}$ conversion exceeding $95 \%$, with $>98 \%$ methanol selectivity over conventional $\mathrm{Cu} / \mathrm{ZnO} / \mathrm{Al}_{2} \mathrm{O}_{3}$ catalysts $[71,73]$. Direct $\mathrm{CO}_{2}$ to methanol conversion is carried out commercially in Iceland using geothermal energy [71,76], however widescale adoption has been limited by the cost of producing green hydrogen and harvesting atmospheric $\mathrm{CO}_{2}$ [69]. Plasma-catalytic hydrogenation of $\mathrm{CO}_{2}$ co-produces $\mathrm{MeOH}, \mathrm{CO}$, and $\mathrm{CH}_{4}$, at mild conditions with low-cost copper/alumina catalyst, achieving $54 \% \mathrm{MeOH}$ selectivity and $11 \% \mathrm{CO}_{2}$ conversion [60]. In thermocatalytic and plasma-driven synthesis of methanol from $\mathrm{CO}_{2}$, carbon monoxide plays a key role as an intermediate species either through electron impact dissociation of $\mathrm{CO}_{2}$ or through the RWGS reaction [60], suggesting the potential development of co-hydrogenation of $\mathrm{CO}_{2} / \mathrm{CO}$ gas mixtures.

Methanol can be converted into olefins with the methanol-to-olefins (MTO) process, producing shortchain alkenes such as ethene and propene [76], which can then be further upgraded to longer chain hydrocarbons [69], or converted to paraffins or aromatic compounds [71,77]. MTO has been carried out at an industrial scale for several years [78]. Recent work has shown that tuning the physical and chemical characteristics of the zeolite catalysts can enable control over product selectivity [71]. These are highly versatile building blocks in hydrocarbon chemistry and provide a route to produce plastics from in-situ resources as depicted in Figure 1. Three established thermochemical pathways can achieve methanol-to-ethanol (EtOH) conversion (1) carbonylation with $\mathrm{CO}$ to produce acetic acid, followed by hydrogenation to $\mathrm{EtOH},(2)$ reductive carbonylation with syngas to produce $\mathrm{EtOH}$ directly, or (3) via methyl nitrite [79]. Emerging tandem catalysis systems can achieve 'one pot' synthesis of ethanol from syngas, producing methanol as an intermediate, which undergoes conversion via the acetic acid pathway in a single reactor, achieving $64 \%$ selectivity for $\mathrm{EtOH}$ and $10 \%$ conversion of $\mathrm{CO}$ [80]. One-step MeOH-to-EtOH conversion using photocatalytic gallium nitride ( $\mathrm{GaN}$ ) that avoids the harsh processing conditions and hazardous reagents required for the conventional routes is also possible [79], however further work is required to scale-up this process. Once converted, dehydration of EtOH to ethylene is relatively straightforward using a mature industrial process capable of achieving $>99 \%$ conversion and selectivity [81]. Clearly there are various approaches to designing the hydrocarbon processing system. This discussion explores some of these possibilities and highlights potential opportunities rather than proposing an ideal system architecture.

\subsection{Nitrogen fixation for agriculture}

Extracted atmospheric nitrogen can be fixed into nitrate-based fertiliser using a plasma catalytic process with oxygen to supply agricultural activities and also used as a buffer gas for breathable 
atmosphere. Plasma-catalytic nitrogen fixation offers the potential to deploy small-scale, modular reactors to provide synthetic fertiliser for Martian agriculture, which would not be possible using the conventional, large-scale Haber-Bosch process $\left(\mathrm{N}_{2}+3 \mathrm{H}_{2} \rightleftharpoons 2 \mathrm{NH}_{3}\right)$ that is typically operated at $>200$ atm and $>400^{\circ} \mathrm{C}$ [11]. Industrial plasma-based nitrogen fixation dates back to the beginning of the twentieth century with the Birkeland-Eyde process, which produced nitric oxide directly from air using a magnetised electric plasma arc driven by hydroelectricity at an energy efficiency of 2.4-3.1 $\mathrm{MJ} / \mathrm{mol}(\mathrm{N})$ [67]. The high energy demand of the process, along with greater maintenance and capital costs, led to its replacement with the HB process $[53,67]$. NTP-based nitrogen fixation can be operated at much lower temperatures and pressures compared to HB [82], reducing the complexity and cost of the process equipment, and enabling modular, scalable production. The scheme in Fig. 1 indicates a generic PC nitrogen fixation process, but could represent the gas-phase PNOCRA process of Hollevoet et al. [57], the two-phase NTP bubble column reactor of Sun et al. [11], or the Birkeland-Eyde process. The PNOCRA process from Hollevoet et al. [57] is similar to the BE process whereby an $\mathrm{O}_{2} / \mathrm{N}_{2}$ gas mixture is converted into $\mathrm{NO}_{\mathrm{x}}$ by an NTP. It makes use of barium oxide to trap $\mathrm{NO}_{x}$, which is then reacted with $\mathrm{H}_{2}$ to form ammonia. The process developed by Sun et al. [11] involves generating a plasma discharge in air bubbled through an electrolyte to produce nitrite and nitrate species, which are subsequently electrochemically converted to ammonium $\left(\mathrm{NH}_{4}{ }^{+}\right)$in solution. Apart from the historical use of $\mathrm{BE}$, there are no commercial-scale nitrogen fixation processes that employ plasma technology, so only lab-scale performance data is available for comparison. Both the PNOCRA and plasma bubble reactor have similar energy consumption, at $4.61 \mathrm{MJ}$ and $4.31 \mathrm{MJ}$ per mol of $\mathrm{NH}_{3}$. However, given the relatively early stage of development for PC nitrogen fixation compared to HB, and the theoretical efficiencies of these processes, it is likely that they will become competitive with conventional ammonia production in the timeframes considered for developing a large-scale Martian settlement.

\subsection{Recycling}

In a resource-scarce environment such as an isolated settlement on Luna or Mars it is essential to maximise recycling of materials and integration of material processes. Some of these are indicated in Fig. 1 by translucent streams. This encompasses obvious opportunities such as using oxygen generated by plants and nitrogen produces by denitrifying soil bacteria for life-support systems, scrubbing and re-using carbon dioxide from human exhalation, and combining additive manufacturing with recycling of printed plastic objects. Less obvious but equally as important is recycling micronutrients and biological products typically disposed of on earth, as these may be much more difficult to source or manufacture in-situ. Here we focus on human urine as an example, and only consider the application on Mars, since it appears unlikely that Lunar agriculture could be sustained without regular supply of agricultural nutrients from Earth [83].

Human urine is potential feedstock for producing fertiliser as it is rich in urea, sodium, potassium, ammonium, calcium, chlorine, sulphate, phosphate, carbonate, creatine, and other organics, whilst low in heavy metals [84], and around 550 L of urine is produced per person, annually, providing a significant opportunity for both nutrient and water recycling. These nutrients are in a form that is readily absorbed by plants, at a similar rate to synthetic fertiliser [84], however they are too dilute to use directly and must be concentrated $[85,86]$. Source-separated urine can be converted to solid agricultural fertiliser using a drying agent comprised of lime and biomass-derived ash, and the applications of low temperatures $\left(<60^{\circ} \mathrm{C}\right)[84,85]$. This process can recover over $90 \%$ of the nitrogen present in urine [86], however in a Martian setting where natural desiccants like wood ash are unavailable, alternative drying agents would be required. Senecal and Vinneras [85] recovered up to $0.44 \mathrm{~kg}$ of nutrients from $20 \mathrm{~kg}$ of urine with an alkaline dehydration process using wood ash, which 
translates into approximately $12.1 \mathrm{~kg}$ of fertiliser per person per year. The requirement for a constant supply of drying agent [84] poses a challenge for ISRU without a non-biomass derived alternative. Other approaches include conventional and solar distillation, and biological or chemical pre-treatment to minimise the bacterial conversion of urea into ammonia [84,87]. Many strategies to deal with the conversion of urea to ammonia by the urease enzyme (found in domestic piping systems) have been investigated, including removing ammonia post-conversion, or pre-treatment to stop the process $[85,86]$. These processes are typically complex, require specialised chemical inputs, and can cause loss of other important nutrients such as phosphorus $[85,86]$. Elevating the temperature and $\mathrm{pH}$ of urine inhibits the urease enzyme activity, effectively arresting the process $[85,87]$ but higher temperatures do lead to greater thermal breakdown of urea into ammonia [86]. An alternative to concentrating urine is to selectively extract the nutrients using industrial separation processes [86]. There is significant potential value from recycling both the water content and agriculturally important nutrients from human urine, which together with synthetic fertiliser production, could improve the viability of Martian agriculture.

\subsection{Mars vs Luna: Different opportunities for ISRU}

The regolith mineral compositions vary significantly between Luna and Mars, offering different opportunities for the refinement and in-situ use of various metal alloys. However, for the purposes of supplying life support, ascent propellant, agricultural inputs, and establishing a foundation for carbonbased chemical processes, this does not make a significant difference. In both cases regolith can be electrolysed to produce oxygen gas and metal alloys. The water present as either mineral hydrates or water ice can be processed as discussed in Section 3.2 as neither the extraction process nor water electrolysis rely on gravity. It is yet unclear whether the microgravity on Luna will pose a challenge for operating molten oxide electrolysis since the analogous Hall-Heroult reactors used on earth rely on buoyancy to remain stably stratified in the presence of electromagnetic forces [88]. The biggest difference between the two locations is the absence of an atmosphere on Luna, meaning there is no abundant source of carbon to build hydrocarbon-based materials, nor is there a source of nitrogen for producing agricultural fertiliser. However, given the proximity of Luna to earth it is conceivable that regular resupply could be a reasonable long-term strategy.

\section{How To Get There from Here: Concluding Remarks and Future Challenges}

At first glance Luna and Mars both appear to be inhospitable, barren landscapes. Finding ways to meet the long-term material needs of human settlers using local resources will facilitate the establishment of self-sufficient settlements. This paper explored the potential for using electrically driven chemical process technology to build an integrated material synthesis and recycling system to support human settlements on Luna and Mars, using in-situ resources. Mature and emerging processes based on electrolysis, electrochemistry, and nonthermal plasma-catalysis were combined with conventional thermochemical processes to supply crucial materials for life-support systems, propellant, agriculture, and manufacturing. Concepts for manufacturing a range of polymers for structural, industrial, and consumer applications were presented, whilst significant opportunities for building complex molecules based on versatile hydrocarbon and nitrogen-based building blocks remain unexplored. The use of recyclable plastics will maximise the material and energy efficiency of the system, as will the recycling of agricultural nutrients and water from human waste. Near-earth asteroids are another potentially rich source of resources, such as water and platinum group metals, which may be valuable as commodities in Earth's global economy, or for supplying Lunar or Martian settlements [14-20]. However, given the additional challenges of extracting and transporting resources from asteroids, exploration of this opportunity is left for future work. 
Great challenges remain before the vision of integrated ISRU present here can be realised. Plasmabased processes are at an early stage of technological readiness, with unresolved challenges for scaleup, reactor design, and catalyst selection [13,52]. Reactor design is crucial for PC processes to maximise synergistic effects arising from plasma-catalyst interactions $[53,60,89]$, resulting in enhanced conversion or yield [90], greater energy efficiency, product selectivity [60], and improved catalyst longevity [91], whilst the choice of catalyst and support material enables the tuning of product selectivity $[58,60]$. Reactors should be designed to enhance plasma-catalyst contact to maximise the use of short-lived active species [92,93]; porous dielectric structures coated in catalyst may offer an advantage here compared to conventional packed bed designs [13,52]. On Earth the transition from emissions-intensive processes to P2X alternatives is limited by cost. Higher costs may be tolerated for space applications provided that these processes can achieve long-term stability, reliability, and deliver on the promise of modularity and versatility. A major practical challenge for electrically driven processes is power consumption, which in both Lunar and Martian settings would likely be supplied from a combination of solar photovoltaics and radioisotope thermoelectric generators. Using P2X to sustain a large settlement will require significant power using current technology, so advances will have to be made in both the provision of power on Mars and Luna, along with the energy efficiency of plasma-catalytic and electrolysis processes. This will progress in concert with advances in materials science to create highly active, selective, and durable catalysts (ideally produced from local resources), as well as durable materials for electrodes. Emerging P2X technology has the potential to contribute to the decarbonisation of Earth's global economy and the enablement of human self-sufficiency in remote locations such as Antarctic research stations, offshore installations, and the surface of Mars.

\section{Vitae}

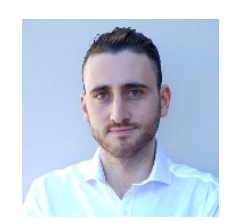

Mark Baldry is a multidisciplinary researcher at the University of Sydney specialising in using multiphysics modelling to understand complex physical systems and design advanced nonthermal plasma technology. As part of the Applied and Plasma Physics research group he is developing plasma surface functionalisation processes and nanotechnology for biomedical applications in sensing, drug delivery, and prosthetic implants. He is also exploring new applications for plasma catalysis and creating new reactor designs to exploit plasma-catalyst synergies. His doctoral research at the University of New South Wales concentrated on the development of thermoelectric-based cryotherapy technology. Dr Baldry has a PhD in mechanical engineering from the University of New South Wales (2019) along with a BE and BSc (2014) from the University of Sydney.

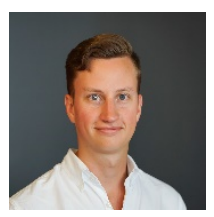

Nicholas Gurieff is an interdisciplinary researcher focused on the design and analysis of energy ecosystems with technoeconomic and multiphysics models. Working with a range of groups, he has explored flow cell energy storage and conversion systems including renewable hydrogen and Powerto-X. His doctoral research at the University of New South Wales concentrated on flow battery technology, improving energy efficiency with novel concepts developed using computer aided design and finite element analysis. He gained operational experience serving as an engineer officer in the 
Royal Australian Navy and has tackled a wide range of other projects. Dr Gurieff has a Ph.D. in mechanical engineering (2020) along with a BE and BA (2014) from the University of New South Wales.

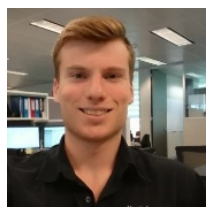

Declan Keogh is a PhD candidate in the School of Mechanical and Manufacturing Engineering at the University of New South Wales. As part of the Energy Storage and Refrigeration research group, he is investigating the fluid mechanics of liquid metal batteries to improve the safety and performance of this scalable energy storage technology. He gained industry experience as a mechanical design engineer working on major Australian infrastructure projects. Mr Keogh has a BE in mechanical engineering (2018) from the University of New South Wales.

\section{References}

[1] L.J. Rothschild, Synthetic biology meets bioprinting: Enabling technologies for humans on Mars (and Earth), Biochem. Soc. Trans. 44 (2016) 1158-1164. https://doi.org/10.1042/BST20160067.

[2] C. Buchner, R.H. Pawelke, T. Schlauf, A. Reissner, A. Makaya, A new planetary structure fabrication process using phosphoric acid, Acta Astronaut. 143 (2018) 272-284. https://doi.org/10.1016/j.actaastro.2017.11.045.

[3] C. Schwandt, J.A. Hamilton, D.J. Fray, I.A. Crawford, The production of oxygen and metal from lunar regolith, Planet. Space Sci. 74 (2012) 49-56. https://doi.org/10.1016/j.pss.2012.06.011.

[4] B.G. Drake, S.J. Hoffman, D.W. Beaty, Human exploration of mars, design reference architecture 5.0, in: IEEE Aerosp. Conf. Proc. IEEE, 2010: pp. 1-24. https://doi.org/10.1109/AERO.2010.5446736.

[5] I.A. Crawford, Lunar resources: A review, Prog. Phys. Geogr. 39 (2015) 137-167. https://doi.org/10.1177/0309133314567585.

[6] R. Daiyan, I. Macgill, R. Amal, Opportunities and Challenges for Renewable Power-to-X, ACS Energy Lett. 5 (2020) $3843-3847$. https://doi.org/10.1021/acsenergylett.0c02249.

[7] J. Gong, N.J. English, D. Pant, G.R. Patzke, S. Protti, T. Zhang, Power-to-X: Lighting the Path to a Net-Zero-Emission Future, ACS Sustain. Chem. Eng. 9 (2021) 7179-7181. https://doi.org/10.1021/acssuschemeng.1c03212.

[8] I.R. Skov, N. Schneider, G. Schweiger, J.P. Schöggl, A. Posch, Power-to-x in denmark: An analysis of strengths, weaknesses, opportunities and threats, Energies. 14 (2021) 1-14. https://doi.org/10.3390/en14040913.

[9] S. Van Alphen, F. Jardali, J. Creel, G. Trenchev, R. Snyders, A. Bogaerts, Sustainable gas conversion by gliding arc plasmas: a new modelling approach for reactor design improvement, Sustain. Energy Fuels. 5 (2021) 1786-1800. https://doi.org/10.1039/d0se01782e.

[10] Z. Cesaro, R.M. Nayak-Luke, R. Banares-Alcantara, Energy Storage Technologies: Power-to-X, in: A. Valera-Medina, R. BanaresAlcantara (Eds.), Techno-Economic Challenges Green Ammon. as an Energy Vector, Academic Press, 2020: pp. 15-26.

[11] J. Sun, D. Alam, R. Daiyan, H. Masood, T. Zhang, R. Zhou, P.J. Cullen, E.C. Lovell, A. (Rouhollah) Jalili, R. Amal, A hybrid plasma electrocatalytic process for sustainable ammonia production, Energy Environ. Sci. 14 (2021) 865-872. https://doi.org/10.1039/d0ee03769a.

[12] S. Van Alphen, V. Vermeiren, T. Butterworth, D.C.M. Van Den Bekerom, G.J. Van Rooij, A. Bogaerts, Power Pulsing to Maximize Vibrational Excitation Efficiency in N2 Microwave Plasma: A Combined Experimental and Computational Study, J. Phys. Chem. C 124 (2020) 1765-1779. https://doi.org/10.1021/acs.jpcc.9b06053.

[13] A. Bogaerts, X. Tu, J.C. Whitehead, G. Centi, L. Lefferts, O. Guaitella, F. Azzolina-Jury, H.H. Kim, A.B. Murphy, W.F. Schneider, T. Nozaki, J.C. Hicks, A. Rousseau, F. Thevenet, A. Khacef, M. Carreon, The 2020 plasma catalysis roadmap, J. Phys. D. Appl. Phys. 53 (2020). https://doi.org/10.1088/1361-6463/ab9048.

[14] O. Poch, I. Istiqomah, E. Quirico, P. Beck, B. Schmitt, P. Theul-, A. Faure, P. Hily-Blant, L. Bona, A. Raponi, M. Ciarniello, B. Rousseau, S. Potin, O. Brissaud, L. ne Flandinet, G. Filacchione, A. Pommero, N. Thomas, D. Kappe, V. Mennella, L. Moroz, V. Vinogradoff, G. Arnold, S. phane Erard, D. Bockel-e-Morvan, C. dric Leyrat, F. Capaccioni, M.C. De Sanctis, A. Longobardo, F. Mancarella, E. Palomba, F. Tosi, Ammonium salts are a reservoir of nitrogen on a cometary nucleus and possibly on some asteroids, Science (80-. ). 367 (2020) 1212. https://doi.org/10.1126/science.aaw7462.

[15] M. Elvis, How many ore-bearing asteroids?, Planet. Space Sci. 91 (2014) 20-26. https://doi.org/10.1016/j.pss.2013.11.008.

[16] A.M. Hein, R. Matheson, D. Fries, A techno-economic analysis of asteroid mining, Acta Astronaut. 168 (2020) $104-115$. https://doi.org/10.1016/j.actaastro.2019.05.009.

[17] V. Hessel, N.N. Tran, S. Orandi, M.R. Asrami, M. Goodsite, H. Nguyen, Continuous-Flow Extraction of Adjacent Metals-A Disruptive Economic Window for In Situ Resource Utilization of Asteroids?, Angew. Chemie - Int. Ed. 60 (2021) 3368-3388. https://doi.org/10.1002/anie.201912205.

[18] L.R.J. Innis, G.R. Osinski, Near-Earth Asteroid Resources: A Review, Geosci. Canada. 46 (2019) 85-100.

[19] M. Jafari Nadoushan, M. Ghobadi, M. Shafaee, Designing reliable detumbling mission for asteroid mining, Acta Astronaut. 174 (2020) 270-280. https://doi.org/10.1016/j.actaastro.2020.05.025.

[20] M.J. Sonter, The technical and economic feasibility of mining, Acta Astronaut. 41 (1998) 637-647.

[21] J. Hartvigsen, S. Elangovan, F. Lyman, MOXIE Development Driven Prospects for ISRU and Atmosphere Revitalization, 48th Int. Conf. Environ. Syst. 8-12 July 2018, Albuquerque, New Mex. 0 (2018).

[22] B. Kading, J. Straub, Utilizing in-situ resources and 3D printing structures for a manned Mars mission, Acta Astronaut. 107 (2015) 317-326. https://doi.org/10.1016/j.actaastro.2014.11.036.

[23] M. Anand, I.A. Crawford, M. Balat-Pichelin, S. Abanades, W. Van Westrenen, G. Péraudeau, R. Jaumann, W. Seboldt, A brief 
[24] S.S. Schreiner, L. Sibille, J.A. Dominguez, J.A. Hoffman, A parametric sizing model for Molten Regolith Electrolysis reactors to produce oxygen on the Moon, Adv. Sp. Res. 57 (2016) 1585-1603. https://doi.org/10.1016/j.asr.2016.01.006.

[25] L.A. Haskin, R.O. Colson, D.J. Lindstrom, R.H. Lewis, W. Semkow, Krystyna, Electrolytic smelting of lunar rock for oxygen, iron, and silicon, in: 2nd Conf. Lunar Bases Sp. Act., Lunar and Planetary Institute, 1992: p. 411.

[26] G. Cesaretti, E. Dini, X. De Kestelier, V. Colla, L. Pambaguian, Building components for an outpost on the Lunar soil by means of a novel 3D printing technology, Acta Astronaut. 93 (2014) 430-450. https://doi.org/10.1016/j.actaastro.2013.07.034.

[27] D. Rapp, Use of extraterrestrial resources for human space missions to moon or Mars, 2nd ed., Springer Praxis Books, 2018.

[28] K.W. Leucht, From Dust to Thrust: How NASA will use robots to create rocket fuel on Mars, IEEE Spectr. (2018) 34-39. https://spectrum.ieee.org/aerospace/robotic-exploration/how-nasa-will-use-robots-to-create-rocket-fuel-from-martian-soil.

[29] J. Bell, The Martian Surface: Composition, Mineralogy and Physical Properties, Cambridge University Press, 2008.

[30] N.K. Ramkissoon, V.K. Pearson, S.P. Schwenzer, C. Schröder, T. Kirnbauer, D. Wood, R.G.W. Seidel, M.A. Miller, K. Olsson-Francis, New simulants for martian regolith: Controlling iron variability, Planet. Space Sci. 179 (2019). https://doi.org/10.1016/j.pss.2019.104722.

[31] A.N. Scott, C. Oze, Y. Tang, A. O'Loughlin, Development of a Martian regolith simulant for in-situ resource utilization testing, Acta Astronaut. 131 (2017) 45-49. https://doi.org/10.1016/j.actaastro.2016.11.024.

[32] R. V. Morris, S.W. Ruff, R. Gellert, D.W. Ming, R.E. Arvidson, B.C. Clark, D.C. Golden, K. Siebach, G. Klingelhöfer, C. Schröder, I. Fleischer, A.S. Yen, S.W. Squyres, Identification of carbonate-rich outcrops on Mars by the spirit rover, Science (80-. ). 329 (2010) 421-424. https://doi.org/10.1126/science.1189667.

[33] C.N. Achilles, R.T. Downs, D.W. Ming, E.B. Rampe, R. V. Morris, A.H. Treiman, S.M. Morrison, D.F. Blake, D.T. Vaniman, R.C. Ewing, S.J. Chipera, A.S. Yen, T.F. Bristow, B.L. Ehlmann, R. Gellert, R.M. Hazen, K. V. Fendrich, P.I. Craig, J.P. Grotzinger, D.J. Des Marais, J.D. Farmer, P.C. Sarrazin, J.M. Morookian, Mineralogy of an active eolian sediment from the Namib dune, Gale crater, Mars, J. Geophys. Res. Planets. 122 (2017) 2344-2361. https://doi.org/10.1002/2017JE005262.

[34] D. Karl, T. Duminy, P. Lima, F. Kamutzki, A. Gili, A. Zocca, J. Günster, A. Gurlo, Clay in situ resource utilization with Mars global simulant slurries for additive manufacturing and traditional shaping of unfired green bodies, Acta Astronaut. 174 (2020) 241253. https://doi.org/10.1016/j.actaastro.2020.04.064.

[35] A. Freundlich, A. Ignatiev, C. Horton, M. Duke, P. Curreri, L. Sibille, Manufacture of solar cells on the moon, Conf. Rec. IEEE Photovolt. Spec. Conf. (2005) 794-797. https://doi.org/10.1109/pvsc.2005.1488252.

[36] C. Vogt, M. Monai, G.J. Kramer, B.M. Weckhuysen, The renaissance of the Sabatier reaction and its applications on Earth and in space, Nat. Catal. 2 (2019) 188-197. https://doi.org/10.1038/s41929-019-0244-4.

[37] S.J. Indyk, H. Benaroya, A structural assessment of unrefined sintered lunar regolith simulant, Acta Astronaut. 140 (2017) 517536. https://doi.org/10.1016/j.actaastro.2017.09.018.

[38] C. Montes, K. Broussard, M. Gongre, N. Simicevic, J. Mejia, J. Tham, E. Allouche, G. Davis, Evaluation of lunar regolith geopolymer binder as a radioactive shielding material for space exploration applications, Adv. Sp. Res. 56 (2015) 1212-1221. https://doi.org/10.1016/j.asr.2015.05.044.

[39] F. Ahmad, E.C. Lovell, H. Masood, P.J. Cullen, K.K. Ostrikov, J.A. Scott, R. Amal, Low-Temperature CO2 Methanation: Synergistic Effects in Plasma-Ni Hybrid Catalytic System, ACS Sustain. Chem. Eng. 8 (2020) 1888-1898.

https://doi.org/10.1021/acssuschemeng.9b06180.

[40] K. Stangeland, D. Kalai, H. Li, Z. Yu, CO2 Methanation: The Effect of Catalysts and Reaction Conditions, Energy Procedia. 105 (2017) 2022-2027. https://doi.org/10.1016/j.egypro.2017.03.577.

[41] K.P. Brooks, J. Hu, H. Zhu, R.J. Kee, Methanation of carbon dioxide by hydrogen reduction using the Sabatier process in microchannel reactors, Chem. Eng. Sci. 62 (2007) 1161-1170. https://doi.org/10.1016/j.ces.2006.11.020.

[42] L.A. Shaw, International Space Station as a Development Testbed for Advanced Environmental Control and Life Support Systems, in: 49th Int. Converence Environ. Syst., Boston, 2019: p. ICES-2019-363. url: http://ecls.de.

[43] S.W. Sheehan, Electrochemical methane production from CO2 for orbital and interplanetary refueling, IScience. 24 (2021) 102230. https://doi.org/10.1016/j.isci.2021.102230.

[44] D. Khetpal, A.C. Ducret, D.R. Sadoway, From oxygen generation to metals production: in situ resource utilization by molten oxide electrolysis, in: 2002 Microgravity Mater. Sci. Conf., 2002: pp. 548-555.

[45] M. Hecht, J. Hoffman, D. Rapp, J. McClean, J. SooHoo, R. Schaefer, A. Aboobaker, J. Mellstrom, J. Hartvigsen, F. Meyen, E. Hinterman, G. Voecks, A. Liu, M. Nasr, J. Lewis, J. Johnson, C. Guernsey, J. Swoboda, C. Eckert, C. Alcalde, M. Poirier, P. Khopkar, S. Elangovan, M. Madsen, P. Smith, C. Graves, G. Sanders, K. Araghi, M. de la Torre Juarez, D. Larsen, J. Agui, A. Burns, K. Lackner, R. Nielsen, T. Pike, B. Tata, K. Wilson, T. Brown, T. Disarro, R. Morris, R. Schaefer, R. Steinkraus, R. Surampudi, T. Werne, A. Ponce, Mars Oxygen ISRU Experiment (MOXIE), Space Sci. Rev. 217 (2021). https://doi.org/10.1007/s11214-020-00782-8.

[46] F.E. Meyen, M.H. Hecht, J.A. Hoffman, Thermodynamic model of Mars Oxygen ISRU Experiment (MOXIE), Acta Astronaut. 129 (2016) 82-87. https://doi.org/10.1016/j.actaastro.2016.06.005.

[47] O. Deutschmann, H. Knozinger, K. Kochloefl, T. Turek, Heterogeneous Catalysis and Solid Catalysts, 3. Industrial Applications, in: Ullmann's Encycl. Ind. Chem., 7th ed., Wiley, 2012: pp. 551-569. https://doi.org/https://doiorg.ezproxy.library.sydney.edu.au/10.1002/14356007.005_003.

[48] S. Lu, Y. Shi, N. Meng, S. Lu, Y. Yu, B. Zhang, Electrosynthesis of Syngas via the Co-Reduction of CO2 and H2O, Cell Reports Phys. Sci. 1 (2020) 100237. https://doi.org/10.1016/j.xcrp.2020.100237.

[49] S. Sarp, S. Gonzalez Hernandez, C. Chen, S.W. Sheehan, Alcohol Production from Carbon Dioxide: Methanol as a Fuel and Chemical Feedstock, Joule. 5 (2021) 59-76. https://doi.org/10.1016/j.joule.2020.11.005.

[50] L. Sibille, J.A. Dominguez, Joule-heated molten regolith electrolysis reactor concepts for oxygen and metals production on the moon and mars, 50th AIAA Aerosp. Sci. Meet. Incl. New Horizons Forum Aerosp. Expo. (2012) 1-11. https://doi.org/10.2514/6.2012-639.

[51] K.D. Grossman, T.S. Sakthivel, L. Sibille, J.G. Mantovani, S. Seal, Regolith-derived ferrosilicon as a potential feedstock material for wire-based additive manufacturing, Adv. Sp. Res. 63 (2019) 2212-2219. https://doi.org/10.1016/j.asr.2018.12.002.

[52] J.C. Whitehead, Plasma-catalysis: The known knowns, the known unknowns and the unknown unknowns, J. Phys. D. Appl. Phys. 49 (2016) 243001. https://doi.org/10.1088/0022-3727/49/24/243001.

[53] H.H. Kim, Y. Teramoto, A. Ogata, H. Takagi, T. Nanba, Plasma Catalysis for Environmental Treatment and Energy Applications, 
[54] R. Zhou, R. Zhou, D. Alam, T. Zhang, W. Li, Y. Xia, A. Mai-Prochnow, H. An, E.C. Lovell, H. Masood, R. Amal, K. (Ken) Ostrikov, P.J. Cullen, Plasmacatalytic bubbles using CeO2 for organic pollutant degradation, Chem. Eng. J. 403 (2021) 126413. https://doi.org/10.1016/j.cej.2020.126413.

[55] R.R. Zhou, T. Zhang, R.R. Zhou, A. Mai-Prochnow, S.B. Ponraj, Z. Fang, H. Masood, J. Kananagh, D. McClure, D. Alam, K. (Ken) Ostrikov, P.J. Cullen, Underwater microplasma bubbles for efficient and simultaneous degradation of mixed dye pollutants, Sci. Total Environ. 750 (2021) 142295. https://doi.org/10.1016/j.scitotenv.2020.142295.

[56] T. Nozaki, K. Okazaki, Non-thermal plasma catalysis of methane: Principles, energy efficiency, and applications, Catal. Today. 211 (2013) 29-38. https://doi.org/10.1016/j.cattod.2013.04.002.

[57] L. Hollevoet, F. Jardali, Y. Gorbanev, J. Creel, A. Bogaerts, J.A. Martens, Towards Green Ammonia Synthesis through PlasmaDriven Nitrogen Oxidation and Catalytic Reduction, Angew. Chemie - Int. Ed. 59 (2020) 23825-23829. https://doi.org/10.1002/anie.202011676.

[58] L. Wang, Y. Yi, C. Wu, H. Guo, X. Tu, One-Step Reforming of $\mathrm{CO} 2$ and $\mathrm{CH} 4$ into High-Value Liquid Chemicals and Fuels at Room Temperature by Plasma-Driven Catalysis, Angew. Chemie - Int. Ed. 56 (2017) 13679-13683. https://doi.org/10.1002/anie.201707131.

[59] E.K. Gibson, C.E. Stere, B. Curran-McAteer, W. Jones, G. Cibin, D. Gianolio, A. Goguet, P.P. Wells, C.R.A. Catlow, P. Collier, P. Hinde, C. Hardacre, Probing the Role of a Non-Thermal Plasma (NTP) in the Hybrid NTP Catalytic Oxidation of Methane, Angew. Chemie - Int. Ed. 56 (2017) 9351-9355. https://doi.org/10.1002/anie.201703550.

[60] L. Wang, Y. Yi, H. Guo, X. Tu, Atmospheric Pressure and Room Temperature Synthesis of Methanol through Plasma-Catalytic Hydrogenation of CO2, ACS Catal. 8 (2018) 90-100. https://doi.org/10.1021/acscatal.7b02733.

[61] G. Akay, K. Zhang, W.S.S. Al-Harrasi, R.M. Sankaran, Catalytic Plasma Fischer-Tropsch Synthesis Using Hierarchically Connected Porous Co/SiO2Catalysts Prepared by Microwave-Induced Co-assembly, Ind. Eng. Chem. Res. 59 (2020) 12013-12027. https://doi.org/10.1021/acs.iecr.0c01585.

[62] S. Mori, N. Matsuura, L.L. Tun, M. Suzuki, Direct Synthesis of Carbon Nanotubes from Only CO2 by a Hybrid Reactor of Dielectric Barrier Discharge and Solid Oxide Electrolyser Cell, Plasma Chem. Plasma Process. 36 (2016) 231-239.

https://doi.org/10.1007/s11090-015-9681-2.

[63] X. Tu, J.C. Whitehead, Plasma-catalytic dry reforming of methane in an atmospheric dielectric barrier discharge: Understanding the synergistic effect at low temperature, Appl. Catal. B Environ. 125 (2012) 439-448.

https://doi.org/10.1016/j.apcatb.2012.06.006.

[64] T. Nozaki, N. Muto, S. Kadio, K. Okazaki, Dissociation of vibrationally excited methane on Ni catalyst: Part 2. Process diagnostics by emission spectroscopy, Catal. Today. 89 (2004) 67-74. https://doi.org/10.1016/j.cattod.2003.11.039.

[65] E. Chiremba, K. Zhang, C. Kazak, G. Akay, Direct nonoxidative conversion of methane to hydrogen and higher hydrocarbons by dielectric barrier discharge plasma with plasma catalysis promoters, AIChE J. 63 (2017) 4419. https://doi.org/10.1002/aic.15769.

[66] T. Nozaki, N. Muto, S. Kado, K. Okazaki, Dissociation of vibrationally excited methane on Ni catalyst: Part 1. Application to methane steam reforming, Catal. Today. 89 (2004) 57-65. https://doi.org/10.1016/j.cattod.2003.11.040.

[67] K.H.R. Rouwenhorst, F. Jardali, A. Bogaerts, L. Lefferts, From the Birkeland-Eyde process towards energy-efficient plasma-based NO X synthesis: a techno-economic analysis, Energy Environ. Sci. 14 (2021) 2520-2534. https://doi.org/10.1039/d0ee03763j.

[68] T. Kozàk, A. Bogaerts, Splitting of $\mathrm{CO} 2$ by vibrational excitation in non-equilibrium plasmas: A reaction kinetics model, Plasma Sources Sci. Technol. 23 (2014). https://doi.org/10.1088/0963-0252/23/4/045004.

[69] J. Ott, V. Gronemann, F. Pontzen, E. Fiedler, G. Grossmann, D. Kersebohm, G. Weiss, C. Witte, Methanol, in: Ullmann's Encycl. Ind. Chem., 7th ed., Wiley, Weinheim, 2012: pp. 1-27. https://doi.org/10.1002/14356007.a16_465.pub3.

[70] J.G. Speight, Handbook of Industrial Hydrocarbon Processes, Gulf Professional Publishing, 2011. https://doi.org/https://doi.org/10.1016/C2009-0-18464-7.

[71] R.P. Ye, J. Ding, W. Gong, M.D. Argyle, Q. Zhong, Y. Wang, C.K. Russell, Z. Xu, A.G. Russell, Q. Li, M. Fan, Y.G. Yao, CO2 hydrogenation to high-value products via heterogeneous catalysis, Nat. Commun. 10 (2019). https://doi.org/10.1038/s41467019-13638-9.

[72] P. Borisut, A. Nuchitprasittichai, Methanol Production via $\mathrm{CO} 2$ Hydrogenation: Sensitivity Analysis and Simulation-Based Optimization, Front. Energy Res. 7 (2019) 1-10. https://doi.org/10.3389/fenrg.2019.00081.

[73] K. Stangeland, H. Li, Z. Yu, CO2 hydrogenation to methanol: the structure-activity relationships of different catalyst systems, Energy, Ecol. Environ. 5 (2020) 272-285. https://doi.org/10.1007/s40974-020-00156-4.

[74] M. Behrens, F. Studt, I. Kasatkin, S. Kühl, M. Hävecker, F. Abild-pedersen, S. Zander, F. Girgsdies, P. Kurr, B. Kniep, M. Tovar, R.W. Fischer, J.K. Nørskov, R. Schlögl, The Active Site of Methanol Synthesis over Cu/ZnO/Al2O3 Industrial Catalysts, Science (80-. ). 336 (2012) 893-898.

[75] M. Muhler, E. Törnqvist, L.P. Nielsen, B.S. Clausen, H. Topsøe, On the role of adsorbed atomic oxygen and CO2 in copper based methanol synthesis catalysts, Catal. Letters. 25 (1994) 1-10. https://doi.org/10.1007/BF00815409.

[76] J. Kothandaraman, A. Goeppert, M. Czaun, G.A. Olah, G.K.S. Prakash, Conversion of CO2 from Air into Methanol Using a Polyamine and a Homogeneous Ruthenium Catalyst, J. Am. Chem. Soc. 138 (2016) 778-781. https://doi.org/10.1021/jacs.5b12354.

[77] J.G. Speight, Hydrocarbons from biomass, in: Handb. Ind. Hydrocarb. Process., Gulf Professional Publishing, Laramie, WY, United States, 2020: pp. 293-342. https://doi.org/https://doi.org/10.1016/B978-0-12-809923-0.00007-2.

[78] P. Tian, Y. Wei, M. Ye, Z. Liu, Methanol to olefins (MTO): From fundamentals to commercialization, ACS Catal. 5 (2015) 19221938. https://doi.org/10.1021/acscatal.5b00007.

[79] M. Liu, Y. Wang, X. Kong, R.T. Rashid, S. Chu, C.C. Li, Z. Hearne, H. Guo, Z. Mi, C.J. Li, Direct Catalytic Methanol-to-Ethanol Photoconversion via Methyl Carbene, Chem. 5 (2019) 858-867. https://doi.org/10.1016/j.chempr.2019.01.005.

[80] I.A. Digdaya, I. Sullivan, M. Lin, L. Han, W.H. Cheng, H.A. Atwater, C. Xiang, A direct coupled electrochemical system for capture and conversion of CO2 from oceanwater, Nat. Commun. 11 (2020) 1-10. https://doi.org/10.1038/s41467-020-18232-y.

[81] M. Zhang, Y. Yu, Dehydration of ethanol to ethylene, Ind. Eng. Chem. Res. 52 (2013) 9505-9514. https://doi.org/10.1021/ie401157c.

[82] G. Akay, Sustainable Ammonia and Advanced Symbiotic Fertilizer Production Using Catalytic Multi-Reaction-Zone Reactors with Nonthermal Plasma and Simultaneous Reactive Separation, ACS Sustain. Chem. Eng. 5 (2017) 11588-11606. https://doi.org/10.1021/acssuschemeng.7b02962. 
[83] F.T. Davies, C. He, R.E. Lacey, Q. Ngo, Growing Plants for NASA - Challenges in Lunar and Martian Agriculture, Comb. Proc. Int. Plant Propagators' Soc. 53 (2003) 59-64.

[84] S. Dutta, B. Vinnerås, Fertilizer from dried human urine added to ash and lime -A potential product from eco-sanitation system, Water Sci. Technol. 74 (2016) 1436-1445. https://doi.org/10.2166/wst.2016.324.

[85] J. Senecal, B. Vinnerås, Urea stabilisation and concentration for urine-diverting dry toilets: Urine dehydration in ash, Sci. Total Environ. 586 (2017) 650-657. https://doi.org/10.1016/j.scitotenv.2017.02.038.

[86] P. Simha, C. Lalander, A. Nordin, B. Vinnerås, Alkaline dehydration of source-separated fresh human urine: Preliminary insights into using different dehydration temperature and media, Sci. Total Environ. 733 (2020) 139313. https://doi.org/10.1016/j.scitotenv.2020.139313.

[87] P. Simha, J. Senecal, D.J.I. Gustavsson, B. Vinnerås, Resource recovery from wastewater, Elsevier B.V., 2020. https://doi.org/10.1016/b978-0-444-64309-4.00009-x.

[88] T. Sele, Instabilities of the metal surface in electrolytic alumina reduction cells, Metall. Trans. B. 8 (1977) 613-618. https://doi.org/10.1007/BF02669338.

[89] K. Zhang, G. Zhang, X. Liu, A.N. Phan, K. Luo, A Study on CO2 Decomposition to CO and O2 by the Combination of Catalysis and Dielectric-Barrier Discharges at Low Temperatures and Ambient Pressure, Ind. Eng. Chem. Res. 56 (2017) 3204-3216. https://doi.org/10.1021/acs.iecr.6b04570.

[90] T. Mizushima, K. Matsumoto, H. Ohkita, N. Kakuta, Catalytic effects of metal-loaded membrane-like alumina tubes on ammonia synthesis in atmospheric pressure plasma by dielectric barrier discharge, Plasma Chem. Plasma Process. 27 (2007) 1-11. https://doi.org/10.1007/s11090-006-9034-2.

[91] Q. Wang, Y. Cheng, Y. Jin, Dry reforming of methane in an atmospheric pressure plasma fluidized bed with Ni/ $\mathrm{Y}$-Al2O3 catalyst, Catal. Today. 148 (2009) 275-282. https://doi.org/10.1016/j.cattod.2009.08.008.

[92] S. Li, W. Zheng, Z. Tang, F. Gu, Plasma heating and temperature difference between gas pellets in packed bed with dielectric barrier discharge under natural convection condition, Heat Transf. Eng. 33 (2012) 609-617.

https://doi.org/10.1080/01457632.2012.630263.

[93] H. Lee, H. Sekiguchi, Plasma-catalytic hybrid system using spouted bed with a gliding arc discharge: $\mathrm{CH} 4$ reforming as a model reaction, J. Phys. D. Appl. Phys. 44 (2011). https://doi.org/10.1088/0022-3727/44/27/274008. 